\title{
Spirituality as an Aid to Promote Health and Well-Being
}

\author{
Salma Kaneez and Shamim A Ansari ${ }^{\dagger}$
}

\section{Abstract}

Spirituality has been described as the central philosophy of life which guides peoples' conduct and is the core of individual existence that integrates and transcends the physical, emotional, intellectual, ethical, volitional and social dimensions. World Health Organization (WHO) has included spirituality in its comprehensive definition of holistic health. It is recognized as a protective factor or resource when dealing with critical illness and disabilities. Spirituality and religious faith exert a primary preventive effect against morbidity in multiple populations, and has a positive association with psychological well-being. A growing body of research has investigated the relationship of various spiritual and religious indices to various aspects of health. Empirical studies have revealed that spirituality and religious beliefs help prevent physical and mental illness, reducing symptoms severity and relapse rate, and enhancing recovery from diverse set of ailments. Spiritual transcendence (connectedness with God) has been found to play crucial role in coping with illness. The purpose of the present article is to explore the role of spiritual and religious practices in promoting health and wellness among the people inflicted with illness. The paper also highlights implications for health practices and future research in complimentary therapies.

Keywords; Spirituality, Well-Being, Coping, Holistic Health.

*UGC Post-Doctoral Fellow AMU, Aligarh, India; ahzam1@yahoo.com tProfessor, Department of Psychology, AMU. Aligarh. 


\section{Introduction}

Recently, there appear prolific instances of application of spirituality as a tool in multidisciplinary studies of health science (e.g. Puchalski, 2001; Koenig, 2009). The concept of spirituality is an emerging paradigm for investigation and a developing area of enquiry involving mind-body-spirit interaction (Moyers, 1993). The spiritual pursuits recommended by religious scriptures have helped in preventing mental and physical disorders in people from ages. However, the traditional, mechanistic biomedical paradigm is being replaced by a broader holistic perspective encompassing biopsychosocial-spiritual factors of health and illness (Dossey, 1995). Spirituality constituting transcendent dimension of human behavior, has assumed greater significance to tackle wholesome health. A growing body of literature has attempted to establish the relationship of various spiritual and religious indices to multiple aspects of health. Research evidences revealed that there is a protective factor of spiritual and religious practices to health and well-being (Koenig, 2000; Schaie, Krause, \& Booth 2004). Spiritual / religious experiences not only help in the treatment of behavioral disorders but also in enhancement of quality of life. Spirituality has been found instrumental to encourage health promoting behavior and to improve clinical condition of the people undergoing medical treatment.

\section{Objective}

The present article aims to assess the role of spiritual / religious practices in promoting health and wellness among the people confronted with diverse set of illnesses. The paper also highlights implications for health practices and future research in complimentary therapies.

\section{Spirituality and Religion}

Spirituality is a sense of wholeness, connectedness and deeper values that have the potential to orient people to work from within. It includes a wide range of human experiences, traditional religions, personal mystical experiences and quest for meaning in 
life. Psychiatrist, Hiatt described the concept of spirituality in psychological terms and relate it to a health care perspective where "spirit refers to that non-corporeal and non-mental dimensions of the person that is the source of unity and meaning, and spirituality refers to the concepts, attitudes and behaviors that drive from one's experience of that dimension" (1986: 746). The most fundamental concept of spirituality is its transcendent dimension to life, something or someone beyond the human ego and sense experience. The experience of connection to this larger sacred reality is what gives our lives ultimate meaning. Therefore, spirituality has to do with a sense of connectedness and interrelatedness. Thus, spirituality is concerned with finding meaning and purpose in life through connectedness with God or a power greater than oneself. It often includes religion, faith system, sacred principles, worship, symbolic meaning, and ritual practices (Denham, 2003).

Spirituality and religiousness are interrelated concepts, yet they are not identical. Spirituality is a broader term and may be viewed as an umbrella concept under which one finds religion (Kaya \& Raghavan, 2002). Religiosity is an expression of one's spiritual perspective and refers to an external formal system of beliefs, values, rules of conduct and rituals. According to Mathews (1996), "religion is an organised system of beliefs, practices and symbols designed to facilitate closeness to God." In other words, spirituality may be perceived as personal views and behaviors that express a sense of relatedness to a transcendent dimension or to something greater than the self that empowers values and integrates the self. While religion aims to foster and nourish the spiritual life, it is possible to adopt the outward forms of religious worship and doctrine without having a strong relationship to the transcendent (Fitzer, 1999a). Some writers, however, have used the terms interchangeably. For example, Koenig (2009) has suggested that spirituality be defined in terms of religion, where religion is multidimensional construct not limited to institutional forms of religion. 


\section{Spirituality, Health and Well-being}

Health is a positive multidimensional state that involves three domains: physical, psychological and social health. World Health Organization (WHO, 1998) added the spiritual dimension to health and defined it as a dynamic state of complete physical, mental, social and spiritual well-being; not merely absence of disease or infirmity. Well-being is the product of complex interplay of biological, socio-cultural, psychological, economic and spiritual factors. Spiritual health is concerned with the enhancement of positive health as well as the treatment and prevention of disease. Spirituality in terms of good mental health and positive psychological or social traits has been found to correlate with mental health and well-being (Koenig, 2009). Multiple studies have shown the positive relationship of spiritual and religious indices on various aspects of health such as cardiac surgery (Ai et al, 1998) mortality (Clark, 1999) and immune function (Woods et al, 1999). Over 250 published empirical studies have appeared in the epidemiological and medical literature in which spirituality has been statistically associated in many ways with particular health outcomes (Levin, 1993). Researchers found spirituality to be a primary resource among persons dealing with chronic disability and illness including hypertension, pulmonary disease, diabetes, chronic renal failure, surgery, arthritis, HIV/AIDS, polio and addictive illnesses (Kaya \&Raghavan, 2002). Miller (1985) found an inverse relationship between loneliness and spiritual well-being among 64 chronically ill and rheumatoid arthritis and healthy adults, and revealed that chronically ill patients had significantly higher spiritual well-being compared to the healthy group. In a qualitative study of chronically ill elderly, Young (1993) concluded that participants' spirituality increased as they aged and became elderly. A feeling of well-being emanated from the belief that God knew their needs and empowered them to continue to survive through difficult times. In AIDS patients, spirituality was perceived as a resource that enhanced personal control and provided a source of comfort.

In addition, numerous studies have investigated the relation between religious activities and well-being. Myers and Diener (1995) in a random survey in sixteen nations reported that religious 
involvement is associated with higher well-being, optimism and positive expectations for future. Koenig (2001) reported that out of 100 studies that examined the association between religious practices and behavior indicators of psychological well-being (life satisfaction, happiness, positive effect and morale), 79 reported at least one significant positive correlation between these variables. This positive association has been consistently similar in samples from different countries involving a diversity of religion, race and age (Lewin et al., 2005). Majority of people participates in some sort of private religious/spiritual activity (e.g. prayer or meditation) as a health intervention. It has been found that individuals used prayer as an unconventional method for treating and coping with their illness. Research on elderly population revealed that religiosity has been associated with lower depression (Kennedy et al, 1996), better physical health (Krause, 1998) and lower alcohol use (Musick, 2000). In sum, literature illustrates spirituality as a positive correlate with both physical health and well-being.

\section{Conclusion and Recommendations}

Spirituality is an important element in the way different populations face chronic illness, sufferings and loss. Stress of illness and disability often cause a disequilibrium of mind, body and spirit that requires coping resources (Soken \& Carson 1987). Spirituality helps the persons cope with the stressful situation especially through the relationship with God and their faith community. While dealing with the crisis they utilize spiritual / religious resources of prayer and meditation which help them to find meaning and purpose in their suffering and a sense of hope for the future. The factors associated with religiosity including optimism, supportive friends, clear purpose and meaning in life and healthier life style correlate with mental and physical wellness. These components lead to less stress, lower blood pressure, better recovery rate and higher immune system (Koenig, et al., 2001). Thus, the religion (as an expression of person's spiritual perspective) exerts primary-prevention effect against morbidity and has a positive association with psychological well-being (Ellison \& Levin, 1998). Therefore, it serves as an aid or valuable resource in facilitating health and well-being. 
Spiritual healing plays a vital role in maintaining harmony, peace, balance, wellness and self-responsibility. As a result, it may form an essential component in rehabilitation profession as part of the complementary and alternative health medicine. An understanding of patient's spirituality is integral to whole patient care, for practices of prayer and meditation act as an adjunct to medical treatment. Spiritual / religious beliefs may affect the decisions patients make about their health and illness. Hence, physicians and health care providers be attentive to all aspects of patients' lives and may incorporate these beliefs into their therapeutic plans accordingly. Interventions and treatment utilizing spirituality need to be individualized and acceptable to the person experiencing disabilities and illness. Indian cultural history is abounding with evidences where spiritual and religious acts were prescribed in order to keep mind-body equilibrium. The results of the aforesaid studies underline the need to exploit the indigenous knowledge resource in future research endeavors.

\section{References}

Ai, A.L., Dunkle, R.E., Peterson, C., Bolling, S.F. (1998). The role of private prayer in psychological recovery among midlife and aged patients following cardiac surgery. Gerontologist, 23(5), 591-61.

Clark, K. M., Friedman, H. S, Martin L. R. (1999). A longitudinal study of religiosity and mortality risk. Journal of Health Psychology, 44(2), 113117.

Denham, S. A. (2003). Family Health: A Framework for Nursing, Philadelphia; F.A. Davis

Dossey, L.(1995) Whatever happened to healers? Alternative Therapies, 1(5), 6-13.

Ellison, C.G. \& Levin (1998). The religion health connection: Evidence, theory \& future direction. Health, Education \& Behavior 25(6) 700-720.

Fitzer /NIA Working Group (1999a). Multidimensional measurement of religiousness /spirituality for use in health research. Kalama zoo, MI: John E. Fetzer Institute.

Hiatt, J. F. (1986). Spirituality, Medicine and Healing. Southern Medical Journal, 79(6),736-43.

Kaya, J. \& Raghavan, S. K. (2002). Spirituality in Disability and illness. Journal of Religion and Health, 41,3231-251. 
Kennedy, G. J., Kelman, H. R., Thomas, C., Chen, J. (1996). The relation of religious performance and practice to depressive symptoms among 1855 older adults. Journal of Gerontology, 51b (6), 301-8.

Koenig, H. J. (2000). Religion, well-being and health in elderly: The scientific evidence for anassociation. In J.A. Thorson (ed.) Perspectives on Spiritual Well-being and Ageing, 84, 97, Springfield, IL; Charless C. Thomas.

Koenig, H. J. (2009). Research on religion, spirituality and mental health: A review. The Canadian Journal of Psychiatry, 54(5), 281-291.

Koenig, H. J. McCullough, M. E., Larson, D. B. (2001), Handbook of Religion and Health. Oxford : Oxford University Press.

Krause, N. (1998). Neighbourhood, deterioration, religious coping and changes in health during late life. Gerontology, 38(6),653-664.

Levin, J. S. (1993). Esoteric vs Exoteric explanations for finding linking Spirituality and Health Advances, The Journal of Mind-Body Health,9(4),54-56.

Lewin, J., Chatters, L. M. and Taylor, R. J. (2005). Religion, health and medicine in African-Americans: Implications for physicians. Journal of National Medical Association, 97(2), 237-49.

Mathews, D. A., McCullough, M. E., Larson D. B., Koenig, H. G., Swyers, J. P. (1998). Religious commitment and health status: A review of research and health implications for family medicine. Archives in Family Medicine, 7, (2) , 91-116.

Miller, J. F. (1985). Assessment of loneliness and spiritual well-being in chronically ill and healthy adult. Journal of Professional Nursing, March-April,79-85.

Moyers, B. (1993). Healing the Mind. New York, Doubleday.

Musick, M. A., Blazer, D. G., Hays, J. C. (2000). Religious activity, alcohol use and depression in a sample of elderly Baptists. Research on Ageing, 22(2), 91-116.

Myers, D. G. \& Diener, E. (1995). Who is happy? Psychological Sciences, 6, 10-19.

Puchalski, C. M. (2001). Role of Spirituality in Health Care. Bayer University Medical Centre Proceedings, 14 (4),352-57.

Schaie, K. W., Krause, N. \& Booth, A. (Eds.) (2004). Religious Influences on Health and Well-being in the Elderly, New York: Springer Publishing Co.

Soken, K., \& Carson, V. (1987). Responding to the spiritual needs of chronically ill. Nursing Clinics of North America, 22(3), 603-611. 
Woods, T. E., Antoni, M. H., Ironson, G. H., Kling, D. W. (1999). Religiosity is associated with affective status in symptomatic HIVinfected African -American Women. Journal of Health Psychology, 4(3), 317-326.

WHO. (1998).WHOQOL and spirituality, religiousness and personal beliefs; WHO Report

Young, C. (1993).Spirituality and the chronically ill Christian elderly. Geriatric Nursing, 14 (6), 298-303. 